\title{
Liner shipping service scheduling and cargo allocation
}

\author{
Koza, David Franz
}

Publication date:

2018

Document Version

Peer reviewed version

Link back to DTU Orbit

Citation (APA):

Koza, D. F. (2018). Liner shipping service scheduling and cargo allocation. Paper presented at Odysseus 2018, 7th international workshop on Freight Transportation and logistics, Cagliari, Italy.

\section{General rights}

Copyright and moral rights for the publications made accessible in the public portal are retained by the authors and/or other copyright owners and it is a condition of accessing publications that users recognise and abide by the legal requirements associated with these rights.

- Users may download and print one copy of any publication from the public portal for the purpose of private study or research.

- You may not further distribute the material or use it for any profit-making activity or commercial gain

- You may freely distribute the URL identifying the publication in the public portal

If you believe that this document breaches copyright please contact us providing details, and we will remove access to the work immediately and investigate your claim. 


\title{
Liner shipping service scheduling and cargo allocation
}

\author{
David Franz Koza \\ Department of Management Engineering, \\ Technical University of Denmark \\ Email: dakoz@dtu.dk
}

\section{Introduction}

We address two problems that affect operational costs as well as the service level of a liner shipping company: The service scheduling problem and the cargo allocation problem.

The service scheduling problem aims at determining optimal port call times of liner shipping services. It is a generalization of the simpler speed optimization problem. Different to previous studies (e.g. Guericke and Tierney, 2015) it does not only determine the speed and fuel consumption between subsequent port calls, but also the weekly berth times at each port. In liner shipping networks the schedules of individual liner shipping services establish the transshipment times between pairs of services that call the same port (Figure 1).

The second problem we address is the cargo allocation problem (CAP) or, synonymously, cargo routing problem. The CAP tries to answer the question of how to route containers through a liner shipping network between their origin and destination.

We solve the service scheduling and the cargo allocation problem together to account for the dependencies between both problems. The objective is to minimize total fuel consumption costs minus total revenues from transporting containers while satisfying transit time requirements for each demand. We call the combined problem the liner shipping

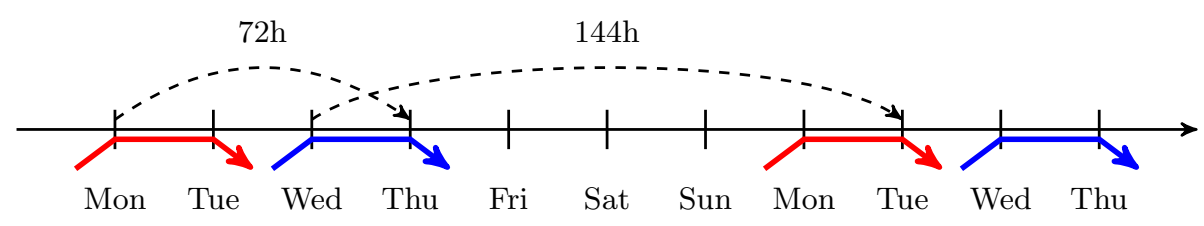

Figure 1: Illustration of schedule dependent transshipment times between two services. The example shows the timeline of a port that is called once per week by each of two different services (red and blue arrows). 
service scheduling and cargo allocation problem (LSSCAP).

The contribution of this work is twofold: First, we present a model and solution method that integrates the service scheduling problem and the cargo allocation problem; the synchronization of individual services and resulting transshipment times are considered explicitly. Second, we consider the vessels' payload in the fuel consumption function and show that neglecting payload may result in suboptimal speed profiles and schedules.

\section{Problem statement}

We consider a given set of services. Each service is defined by a sequence of port calls that define the sailing route of the service and a total duration in weeks, which is equal to the number of vessels operating the (weekly) service. Multiple port calls for the same port may exist. The number of sailing legs on each service equals the number of port calls.We are further given a set of all origin-destination demands defined by a number of containers and a unit revenue for each container if transported. Furthermore, a transit time limit defining a maximum duration between pick-up and delivery is given for every demand.

The goal is to simultaneously find a feasible schedule for each service and to allocate cargo to the services such that the total fuel consumption cost minus the revenues from transporting cargo are minimized. A schedule is feasible if the total round trip time (in weeks) equals the deployed number of vessels and if the speed restrictions of the deployed vessel class are satisfied on each sailing leg. A cargo path is only feasible, if the total transit time including transshipment times at ports (if applicable) does not exceed the maximum transit time of the corresponding demand.

\section{Model and solution method}

We model the problem over a time-space graph as illustrated in Figure 2. Each vertex represents a port call of a particular service at a particular time. Vertices are connected by directed sailing arcs, if the port call of the destination vertex follows the port call of the origin vertex for a given service, and if the sailing time associated with the arc is feasible. Vertices that represent the same port are connected by transshipment arcs that represent movement in time only. If a cargo path uses a transshipment arc, the containers are transshipped between two different services (vessels) at the corresponding port.

We present a branch-and-price algorithm with an integrated primal heuristic to solve the problem. The pricing problem is a resource constrained shortest path problem and we use a label setting algorithm to solve it. The primal heuristic is invoked at each node in the branch-and-bound tree (if not pruned). It first determines a feasible schedule for all services in the network by solving a binary integer programming model. In the second step 
Service 1

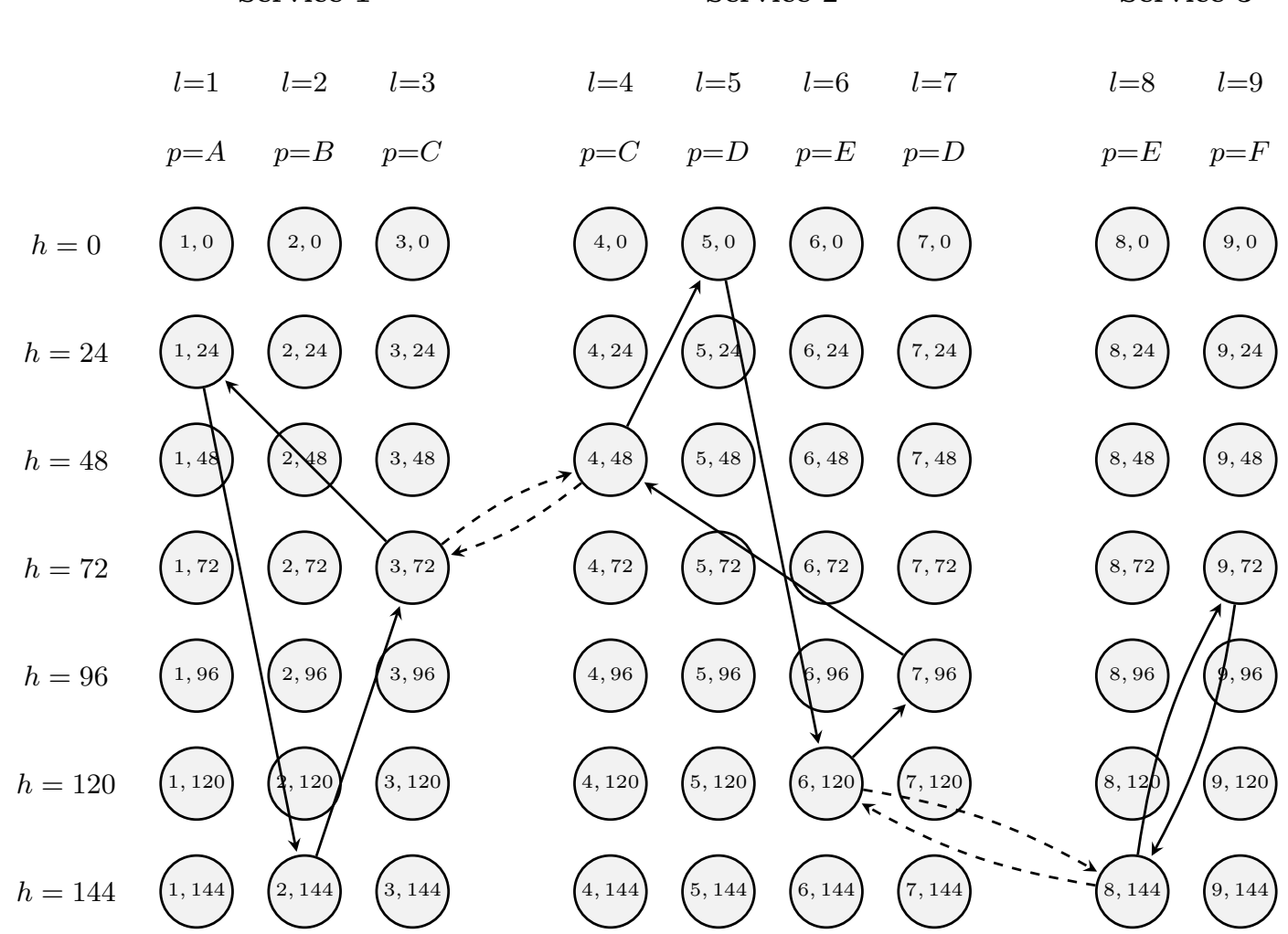

Figure 2: Time-space graph to model the problem. The displayed arcs represent one feasible solution to the scheduling problem. The solid arcs represent scheduled sailings, whereas the dashed arcs represent transshipments of containers between services.

the optimal cargo allocation is determined by solving a multi-commodity flow problem. The primal heuristic generates a feasible solution to the LSSCAP at each node if invoked.

\section{Results and conclusion}

The branch-and-price solution algorithm is tested on four (unscheduled) liner shipping networks of different size and different transit time restrictions on the origin-destination demands. For small and medium sized networks, the found solutions are close to optimal $(<0.5 \%$ gap). For large problem instances larger gaps remain; the integrated primal heuristic, however, quickly finds feasible solutions.

The results show that the approximation of transshipment times (as used in previous studies) can lead to over- or underestimation of cargo transit times. If demands are subject to transit time limits, the underestimation of cargo transit times results in overly optimistic solutions in terms of transported cargo and revenues. Figure 3 compares solution key performance indicators (KPI) for different transshipment time approximation values $(48 \mathrm{~h}$, 


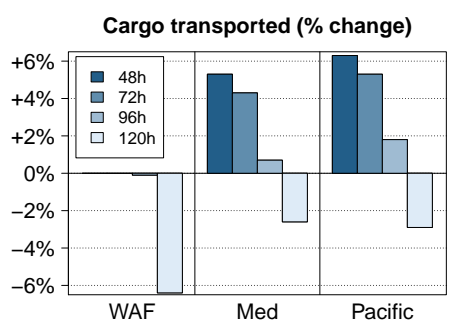

(a) Number of containers transported

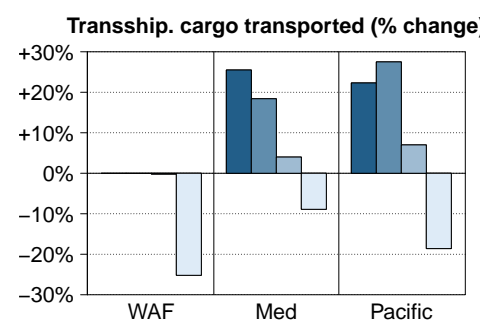

(b) Number of transshipped containers transported

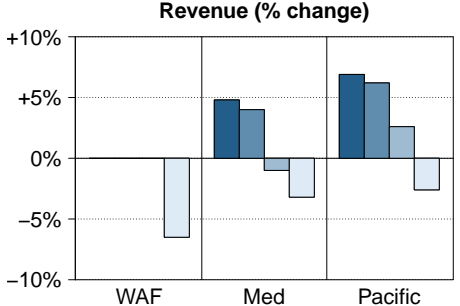

(c) Revenue

Figure 3: Comparison of constant transshipment time values against exact transshipment times and how they influence solution KPIs in comparison to the exact model (in \%).

Speed (knots) per sailing leg

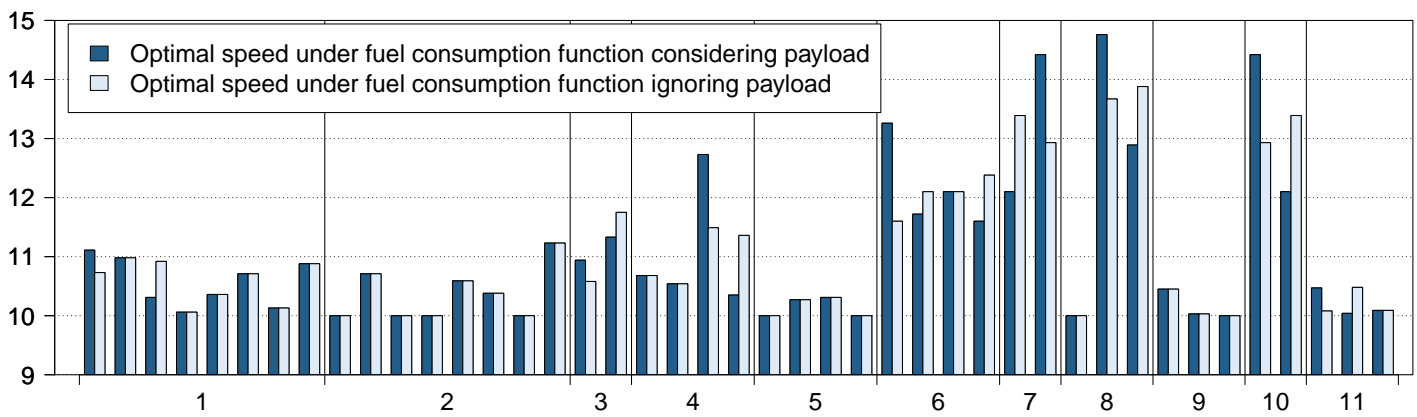

Figure 4: Sailing speed per leg in the best found schedules for a network of 20 ports and 11 services. The bar plot is divided by services and the x-axis labels denote the service.

$72 \mathrm{~h}, 96 \mathrm{~h}$ and $120 \mathrm{~h})$ to the values of the exact model, i.e. the bar plots report relative deviations (in \%) in comparison to the proposed exact model.

We further analyse the impact of payload on the fuel consumption function and compare results against the case in which payload is neglected, as done in the majority of liner shipping studies. Figure 4 compares the optimal speed on different sailing legs under a simple speed-only dependent fuel consumption function and under a payload dependent fuel consumption function. The results show that the optimal speed per leg may vary between the two fuel consumption functions. Thus, neglecting vessel payloads may not only lead to miscalculated costs, but it may actually result in suboptimal speed profiles.

\section{References}

[1] S. Guericke and K. Tierney, "Liner shipping cargo allocation with service levels and speed optimization", Transportation Research Part E: Logistics and Transportation Review 84, 40-60, 2015. 